\title{
MINAS GERAIS NO CONTEXTO DAS INDICAÇÕES GEOGRÁFICAS (IGs) BRASILEIRAS
}

\author{
Minas Gerais in the context of brazilian geographical indications (Gls)
}

Minas Gerais en el contexto de las indicaciones geográficas (IGs) brasileñas

Guilherme Henrique dos Santos Santana *
Marcelo Cervo Chelotti **

* Mestrando no Programa de Pós-Graduação da Universidade Federal de Uberlândia (PPGEO-UFU) guilherme_santana01@hotmail.com

** Docente do Departamento de Geociências da Universidade Federal de Santa Maria (DGEO-UFSM) mcervochelotti@gmail.com

\author{
Recebido em 11/03/2021. Aceito para publicação em 09/06/2021. \\ Versão online publicada em 09/08/2021 (http://seer.ufrgs.br/paraonde)
}

Como citar este artigo: SANTANA, G. H dos. S. CHELOTTI, M .C. Minas Gerais no contexto das indicações geográficas (IGs) brasileira.. Para Onde!?, v. 15, n. 1, p. 57-76, 2021.

\section{Resumo:}

As Indicações Geográficas (IGs) estão presentes em todo território brasileiro e possuem diversas características, como tradições, áreas de abrangência e produtos certificados. Em 2020 eram 79 IGs, sendo 57 Indicações de Procedência e 22 Denominação de Origem, resultando em complexas certificações que alteram 0 território que estão inseridas. A gênese no Brasil ocorre em 2002 com a IG do Vale dos Vinhedos, e desde então, há um aumento das discussões sobre a certificação. $O$ objetivo do artigo é apresentar as principais características e tipologias das Indicações Geográficas no país, mas em especial no estado de Minas Gerais. A metodologia se deu com revisões bibliográficas e análises de dados secundários em diversas plataformas, tais como, DataSebrae, IBGE, INPI, dentre outras. Em Minas Gerias são 10 Indicações Geográficas, com grande potenceial nas suas certificações, desde 0 tradicional Queijo Canastra, com raízes históricas, ao moderno Café do Cerrado, associado ao mercado global. Percebemos assim, a íntima relação entre a Indicação Geográfica e a categoria território, com predomínio nas regiões sul e sudeste.

Palavras-chave: Indicação Geográfica. Território. Certificação. Tipologia. Minas Gerais.

\begin{abstract}
:
Geographical Indications (Gls) are present throughout the Brazilian territory and have several characteristics, such as traditions, coverage areas, and certified products. In 2020, there were 79 Gls, 57 of them being Indications of Origin and 22 Denomination of Origin, resulting in complex certifications that change the territory where they are inserted. The genesis in Brazil occurs in 2002 with the GI Vale dos Vinhedos, and since then, there has been an increase in discussions about certification. The objective of this article is to present the main characteristics and typologies of Geographical Indications in the country, but especially in the state of Minas Gerais. The methodology was based on bibliographic reviews and analysis of secondary data in various platforms, such as DataSebrae, IBGE, and INPI, among others. In Minas Gerais there are 10 Geographical Indications, with great potential in their certifications, from the traditional Canastra cheese, with historical roots, to the modern Cerrado coffee,
\end{abstract}


associated with the global market. Thus, we perceive the close relationship between Geographical Indication and territory category, with predominance in the south and southeast regions.

Keywords: Geographical Indication. Territory. Certification. Typology. Minas Gerais.

\begin{abstract}
Resumen:
Las Indicaciones Geográficas (IG) están presentes en todo el territorio brasileño y tienen varias características, como tradiciones, áreas de cobertura y productos certificados. En 2020, había 79 IG, 57 de las cuales eran Indicaciones de Origen y 22 Denominaciones de Origen, lo que se traduce en certificaciones complejas que cambian el territorio donde se insertan. La génesis en Brasil se produce en 2002 con la IG de Vale dos Vinhedos, y desde entonces se multiplican los debates sobre la certificación. El objetivo del artículo es presentar las principales características y tipologías de las Indicaciones Geográficas en el país, pero especialmente en el estado de Minas Gerais. La metodología se basó en revisiones bibliográficas y análisis de datos secundarios en diversas plataformas, como DataSebrae, IBGE, INPI, entre otras. En Minas Gerais existen 10 Indicaciones Geográficas, con gran potencial en sus certificaciones, desde el tradicional Queso de Canastra, con raíces históricas, hasta el moderno Café de Cerrado, asociado al mercado global. Así, se percibe la estrecha relación entre la Indicación Geográfica y la categoría de territorio, con predominio en las regiones del sur y del sureste
\end{abstract}

Palabras clave: Indicación Geográfica. Territorio. Certificación. Tipología. Minas Gerais.

\title{
1. Introdução
}

Nas últimas décadas pode-se perceber como as discussões sobre as Indicações Geográficas (IGs) vem se expandindo no território nacional, essas que permeiam diferentes áreas de conhecimento, como o Direito, visto as características de direito intelectual; a Economia, em que há debates sobre nichos de mercado e valor agregado de produtos; Biotecnologia; Agronomia, dentre outros. Na Geografia não é diferente, os debates acerca dessas certificações se ampliam e enraízam nas suas diferentes vertentes e áreas.

Nota-se o diálogo entre as Indicações e a Geografia desde análises sobre as características físicas em que a certificação está inserida, como as condições do solo, altitude e pluviosidade, além de uma análise geopolítica e da Geografia Econômica, a exemplo os poderes por trás da certificação; mercado local e o global; diálogos e arranjos territoriais da Indicação Geográfica. Além das duas vertentes apresentadas, é possível também levantar um diálogo com a Geografia Rural e Urbana, visto a complexa e intrínseca relação de ambos, onde os produtos centrais são desenvolvidos; a Geografia Cultural, tendo base as questões históricas e tradicionais ligadas a determinadas IGs, dentre outras áreas. Percebe-se então uma amplitude de discussões e análises, essas que serão apresentadas no decorrer do artigo.

As Indicações Geográficas estão presentes em todo território nacional e possuem diversas características, com diferentes produtos e arranjos territoriais, as mesmas modificando os territórios as quais estão inseridas. Em uma escala mundial, atribuir valor a determinado produto pode ser observado desde tempos bíblicos, 
porém, a primeira Indicação Geográfica datada, ainda no século XVIII, foi a IG de Porto, em Portugal, tendo como produto central o vinho. No Brasil a primeira certificação se deu em 2002, a IG do Vale dos Vinhedos (vinho), já em Minas Gerais, estado que possui centralidade no artigo, a primeira IG ocorre em 2005, a IG da Região do Cerrado Mineiro (café).

O artigo tem como objetivo apresentar os principais pontos, características e tipologias acerca das Indicações Geográficas no Brasil, em especial no estado de Minas Gerais, além de apresentar uma análise sobre a gênese das Indicações Geográficas no país e a relação IG com a categoria geográfica território.

O arcabouço metodológico se deu em duas etapas: no primeiro momento ocorreu um levantamento bibliográfico sobre os principais temas do artigo com seus respectivos autores, como exemplo: Falcade (2005), Niederle e Vitrolles (2010), Caldas (2019) sobre as Indicações Geográfica e Souza (2000; 2009) sobre a categoria geográfica Território, a qual possuirá centralidade no trabalho. No segundo momento se deu uma pesquisa documental com a coleta de dados secundários, acessando plataformas e bancos de dados como a Produção Agrícola Municipal do Instituto Brasileiro de Geografia e Estatística (PAM/IBGE), a Fundação João Pinheiro do Governo de Minas Gerais, o Instituto Nacional de Propreidade Industrial (INPI), dentre outros.

O presente texto está organizado em cinco partes, a primeira apresenta as origens e perspectivas das certificações, expondo sua definicição, seus pontos principais, bem como suas características base. Na segunda parte foi dedicado uma análise sobre a Indicação Geográfica e a categoria território. Na terceira e quarta parte foi enunciado, respectivamente, as Indicações Geograficas no Brasil e as tipologias da mesmo no país. Na quinta parte é apresentado de maneira aprofundada as Indicações Geográficas no estado de Minas Gerais, bem como seus atributos.

\section{Origens e perspectivas da Indicação Geográfica}

As Indicações Geográficas (IGs) estão presentes no território brasileiro e se dispõem das mais diversas características, elas se localizam em diferentes regiões do país e estão presentes do urbano ao rural; do artesanato aos produtos agroalimentares; de uma produção familiar até uma produção globalizada, ou seja, percebemos, inicialmente, como essas IGs são complexas e nos levam a diversas indagações, por exemplo, como se estabeleceram e se organizaram no território brasileiro.

Deve-se, primeiramente, ressaltar que todo processo de certificação e estabelecimento das IGs, no Brasil, ocorre por meio do INPI, ou seja, esse instituto possui uma centralidade desde o pedido de diversas associações e cooperativas, para que seja instaurada uma IG, até sua posterior constituição, observando-a e garantindo a certificação e a manutenção das qualidades que fizeram determinada região conseguir essa procedência.

Portanto, de antemão, é importante compreender a função do Governo para que ocorra as certificações, o qual desempenha um papel central na organização e na concessão por meio do INPI. Diante disso e, percebendo essas dinâmicas acerca 
da IG, é fundamental compreendermos a sua definição, ou melhor, as suas definições.

A Indicação Geográfica (IG) é um ativo de propriedade industrial usado para identificar a origem de um determinado produto ou serviço, quando o local tenha se tornado conhecido, ou quando certa característica ou qualidade desse produto ou serviço se deva à sua origem geográfica (INPI, 2019).

Segundo o INPI, as IGs têm como características identificar a gênese de um produto, ou seja, de acordo com sua origem, perceber as particularidades do produto possui e como essas alteram o território, muitas vezes, deixando conhecido ou marcado por certos produtos ou, em outros casos, o território passa a oferecer atributos singulares que formam produtos únicos e totalmente diferenciado dos demais.

Essas duas formas diferenciadas de identificar e reconhecer as características de um produto, geram a existência de duas formas de certificação diferentes, em síntese, a existência de duas formas de IG: a Indicação de Procedência e a Denominação de Origem:

Por IP, entende-se o nome geográfico de país, cidade, região ou localidade de seu território, que se tornou conhecido como centro de extração, produção ou fabricação de determinado produto ou de prestação de determinado serviço. E, por DO, o nome geográfico de país, cidade, região ou localidade de seu território, que designe produto ou serviço cujas qualidades ou características se devam exclusiva ou essencialmente ao meio geográfico, incluídos fatores naturais e humanos (INPI, 2019).

Como proposto pelo INPI, as IGs podem se dar tanto por Indicação de Procedência - quando uma região é conhecida pelo produto gerado por ela, como por exemplo, a IG do Queijo Canastra, na qual o queijo, ligado a uma produção artesanal com ingredientes, como o leite, de propriedade elevada, gera um forte reconhecimento como uma região produtora de queijo de alta qualidade, que espalha esse "status" por todo território nacional e, até mesmo, além de suas fronteiras - como também a IG pode-se dar por Denominação de Origem, na qual sejam gerados produtos de qualidades extremamente específicos, em outras palavras, que o território ofereça certas singularidades que deixam esse produto com características únicas. Temos como exemplo a IG da Região do Própolis Verde de Minas Gerais, cujo produto central é a própolis verde, nesse caso, a soma de altas altitudes (900 a 1.500 metros), somados a um solo ácido e a plantas especificas, geram uma própolis única, produzida somente nessa região.

Temos também dois casos especiais, as IGs do Vale dos Vinhedos e da Região do Cerrado Mineiro, tendo como produto central, respectivamente, o vinho e o café. Essas IGs atribuíram, em lapsos temporais diferentes, tanto a Indicação de Procedência como também a Denominação de Origem, ou seja, possuem as duas formas de certificação existentes: regiões reconhecidas pelos seus produtos e respectivos territórios, oferecendo características singulares para produtos únicos e de alta qualidade. 
Percebemos, então, como essas Indicações alteram os meios as quais estão inseridas, atribuindo valor ao seu território.
A proteção concedida por uma IG, além de preservar as tradições locais, possui o potencial de diferenciar produtos e serviços, melhorar o acesso ao mercado e promover o desenvolvimento regional, gerando efeitos para produtores, prestadores de serviço e consumidores (INPI, 2019).

Como apresentado, os benefícios para instaurar a IG vão desde aspectos culturais, preservando as tradições locais e os produtos gerados por esses grupos, como também por aspectos econômicos, com acesso ao mercado, conseguindo chegar a novos nichos e ao crescimento econômico, mesmo que, muitas vezes, esse crescimento seja limitado a certos grupos específicos. Ainda com as reflexões acerca das definições das IGs:

\section{(...) são reconhecidas como uma estratégia de qualificação que enfatiza o enraizamento sociocultural do produto no território onde este é produzido. Ao qualificar ativos intangíveis que são de difícil transposição para outros territórios, as IGs podem mesmo ser conceitualmente percebidas como um catalisador de processos de desenvolvimento territorial (...) (NIERDELE; VITROLLES, 2010, p. 5).}

Nierdelle e Vitrolles (2010) apresentam como a Indicação Geográfica está diretamente ligada ao Território e as características que ele possui pelo fato de influenciar no processo de certificação e se transformar com os processos que essa mesma certificação pode gerar. Os autores ainda evidenciam um produto gerado por esse Território, que é de difícil transposição, ou seja, que possui especificidades.

Percebe-se então a Indicação Geográfica como arranjo territorial de diferentes poderes, sendo esses desde o agricultor no caso de IGs ligado a produtos agroalimentares até o Estado, representado, por exemplo, pelo INPI para levar ao desenvolvimento, à transformação de um território.

\section{A Indicação Geográfica e sua relação com o território}

Como exposto anteriormente, a categoria geográfica Território possui centralidade no artigo proposto. Assim, é essencial compreendermos as definições que cercam essa categoria de análise, bem como as discussões e interpretações geradas por ela.

Segundo Souza (2000), uma das principais conceituações acerca do território é a de espaço definido e delimitado por e a partir das relações de poder, ou seja, o território é uma categoria de análise diretamente ligada ao exercício do poder, sendo esse atribuído ao Espaço Geográfico.

Ainda na definição de território, segundo Souza (2000), a categoria surge na tradicional Geografia Política e tem com como grande autor e fundamentador o geógrafo alemão Friedrich Ratzel. Ratzel propõe uma definição de território ligada às relações de poder, sendo, entretanto, um poder ligado ao campo político, um poder político do Estado.

Nessa percepção apresentada, o território se remete então, a um pensamento muito vinculado ao poder do Estado, inclusive, sendo muitas vezes apresentado e 
discutido como "território nacional", ou seja, um poder ligado ao político, às raízes e identidades, devido ao grande poder exercido pelo Estado, o qual é visto até os dias de hoje.

Porém, é possível notar com o passar das décadas, uma evolução conceitual do território, com novas abordagens e perspectivas sendo apresentadas ao longo dos anos, proposta por muitos autores, como Milton Santos, Marcelo Lopes de Souza, Rogério Haesbaert, Marcos Saquet, dentre outros. Nessa evolução conceitual, foi possível perceber que o poder e os agentes hegemônicos que exercem esse poder sobre determinado espaço, ainda têm uma influência gigantesca do político, porém, deve-se perceber, também, a presença de outros poderes, como o poder econômico e o poder cultural, ambos sendo fundamentais para compreensão do território, bem como as transformações dele.

O que "define" o território é, em primeiríssimo lugar, o poder - e, nesse sentido, a dimensão política é aquela que, antes de qualquer outra, Ihe define o perfil. Isso não quer dizer, porém, que a cultura (o simbolismo, as teias de significados, as identidades...) e mesmo a economia (o trabalho, os processos de produção e circulação de bens) não sejam relevantes ou não estejam "contemplados" ao se lidar com o conceito de território a partir do enfoque que propus em 1995, e que depois retomei (ver, por exemplo, Souza [2006, subcapítulo 5.2 da Parte II]) (SOUZA, 2009, p. 59).

Como proposto por Souza (2009), o território, para ser entendido em toda sua complexidade e dinâmicas presentes, deve também ter um olhar sobre a cultura e a economia, sem deixar de perceber as atuações do poder político.

Ao apresentar a influência da economia, mostra como é fundamental compreendê-la sobre um território, sobretudo perante a um mundo globalizado, que lança estratégias, impõe um tempo e se põe como um grande hegemônico. Ademais, é necessário compreender a influência da cultura, a mesma que exerce muito poder ao território, indo desde de "novas tendências" às residualidades e ao tradicional, dotada de identidades, costumes e simbolismos.

Isso nos fazendo levar a mais uma reflexão:

Aliás, a própria separação entre o "político", o "cultural" e o "econômico", da maneira como amiúde é feita, tem muito de cartesiana, de artificialmente preocupada em separar aquilo que é distinguível mas não é propriamente separável (SOUZA, 2009, p. 60).

Como apresentado no trecho, a separação entre o político, a cultura e o econômico é um equívoco, pois um é fundamental ao outro. Em certos casos, um é essencial para compreensão do outro, logo, como proposto por Souza (2009), podemos distingui-los, visto as particularidades existentes entre eles, mas não separá-los.

Em síntese, temos que compreender o território sendo tão complexo como ele realmente é, apresentando os diversos poderes que podem ser exercidos sobre determinado espaço e como muitas vezes esses poderes podem estar interligados. Um exemplo interessante de observar o exercício desses poderes no território e como eles se contemplam é por meio das Indicações Geográficas. Com as certificações, todo um arranjo territorial acontece e, nele, percebemos vários agentes atuando sobre um mesmo território. 
Nas IGs, percebemos a presença do poder político, o qual atua fortemente sobre as indicações e sobre os territórios as quais estão presentes. Um exemplo desse poder político é a presença do INPI, um instituto governamental norteador sobre as certificações, que observa os padrões e as características de cada uma. Outro exemplo desse poder político é a presença do Governo em certas certificações com financiamento de pesquisas por meio da EMBRAPA (Empresa Brasileira de Pesquisa Agropecuária), como também através de políticas de crédito rural (exemplo de poder político associado a um poder econômico), sendo esse crédito realidade em algumas indicações, como exemplo, produtores de Café da Região do Cerrado Mineiro.

Ainda nas IGs, nota-se também a presença do poder econômico, perceptível desde um desenvolvimento econômico local. Em algumas indicações (a exemplo, a Indicação Geográfica de São Tiago, cujo produto central é o biscoito, influencia toda economia local, bem como o desenvolvimento de pequenos comércios) até um poder econômico que visa o lucro global, em que certas indicações, como o Café da Região do Cerrado Mineiro, têm um desenvolvimento de seu produto ligado ao mercado internacional, o qual é inerente ao meio técnico-científico-informacional.

Como presença, também desse poder econômico, dentro das Indicações Geográficas e dos territórios, as quais as certificações estão presentes, percebemos as figuras dos bancos, desde os pequenoscooperados até grandes redes financeiras internacionais, os quais são, muitas vezes, financiadoras dos processos produtivos que geram os produtos centrais das IGs.

Mais uma relação existente se dá por meio do crescimento comercial que as indicações geram, visto que esses produtos possuem qualidades singulares, os quais são atrativos a vários nichos de mercado dentro de um mundo globalizado. $O$ que leva a reflexão que, mesmo em um mundo globalizado, de características à homogeneização e busca pela padronizado, percebemos que o diferente também é atrativo e apreciado, portanto, as Indicações Geográficas são provas de que, mesmo no global, o singular também pode ser referenciado.

Até o primeiro semestre de 2020 haviam 79 Indicações Geográficas reconhecidas pelo INPI, as quais desenvolvem economicamente, o comércio, os bancos e as elites locais nas diversas configurações que elas estão representadas, desde o mercado local ao internacional. São relações econômicas, tanto as de produção artesanal - Cachaça de Salinas - até uma produção ligada ao mecanizado e ao global - Café do Cerrado Mineiro. Todos apresentam um grande arranjo territorial.

Por fim, além do poder político e econômico, temos também o poder cultural, assim como os anteriores, fundamental sob um território e nas suas eventuais transformações. As IGs são grandes palcos desse poder cultural, pois muitos dos seus produtos únicos e se deram por meio de questões históricas e saberes familiares ou de certas comunidades, as quais o cultural é presente pelas simbologias que diversas certificações trazem, além dos ensinamentos que foram passados.

Como apresentado, muitas indicações têm seus produtos centrais ligados a ensinamentos históricos e saberes culturais, temos como exemplo a IG de São João del Rei. 
O artesanato em estanho de São João Del Rei tem características barrocas, peças sacras e os utensílios domésticos possuem design colonial. $O$ estanho de design colonial é um produto que reforça a identidade cultural de São João Del Rei. Nas peças sacras, são mantidas as formas arredondadas da religiosidade são-joanense. Estes aspectos agregam valor ao produto na medida em que o estanho traz a representação da cidade em si (DATASEBRAE, 2018).

Como observado, ao descrever o artesanato em estanho - produto central da IG de São João del Rei - é possível perceber todo um detalhamento histórico e cultural do processo e do produto gerado, além de mostrar como essas etapas foram determinantes para se estabelecer dessa forma. Outro aspecto importante é como o autor utiliza do histórico e do cultural como argumento para um produto de valor agregado e, um dos desdobramentos desse valor agregado e singularidade gerada, é o interesse do mercado em adquirir tal produto, ou seja, um exemplo de como o cultural e o econômico se relacionam, reforçando a ideia de como não podemos pensar os agentes sobre o território de forma separada.

Outro exemplo da importância do cultural se dá por meio das tradições levadas pelas pessoas que produzem determinado produto, como os grupos de pessoas que migraram para o desenvolvimento dos determinados cultivos ou pessoas as quais a produção de determinado produto está inserida no seu dia a dia. Como exemplo das citações anteriores, temos, no primeiro caso a Região do Cerrado Mineiro, onde a produção do Café se deu com a migração de paranaenses para região do Oeste do estado de Minas Gerais. Os paranaenses trouxeram consigo diversos costumes, os quais foram inseridos e combinados aos costumes locais, levando à pluralidade cultural. No segundo exemplo de produção que está inserida no cotidiano e, muitas vezes, se torna algo intrínseco da pessoa, temos o Queijo Canastra, cuja produção artesanal foi passada de geração a geração e coloca o queijo como "parte de um mineiro", sendo continuadamente colocado como símbolo e parte de sua essência.

Desse modo, notamos como a política, economia e cultura agem sobre o território e sobre as IGs, as quais transformam os territórios e esses, por sua vez, oferecem características para que as certificações ocorram.

\section{Indicações Geográficas no Brasil}

Tanto no Brasil como no mundo, discutir o início das Indicações Geográficas é muito complexo devido a diversos produtos que, historicamente, foram conhecidos pelas suas qualidades e peculiaridades, como também tiveram centralidade em determinadas regiões.

Segundo o INPI (2019), prova dessa complexidade quanto a gênese das Indicações Geográficas, são os produtos conhecidos por suas origens e por suas qualidades, os quais vêm desde os tempos bíblicos. Porém, oficialmente, a primeira intervenção estatal se deu apenas em meados do séc. XVIII, reconhecendo, assim, em Portugal, o nome Porto para vinhos localizados naquela região do país e que dispunham das qualidades que se encaixariam como características da região, em síntese, a primeira Indicação Geográfica.

Isso nos leva a duas reflexões: a primeira é a importância da implementação

Para0nde!?, Porto Alegre, v.15, n.1, p.57-76, 2021. http://seer.ufrgs.br/paraonde 
da Indicação Geográfica, que além de ser um modelo de proteção de qualidade, gera também um aparato aos produtores, mostrando a eles a proteção governamental sobre os produtos centrais produzidos, garantindo a qualidade singular que os produtos possuem: "A implementação de uma Indicação Geográfica está ligada às necessidades da sociedade, como fato e condição de um processo que é, ao mesmo tempo, político, econômico, social e ambiental" (FALCADE, 2005, p. 40).

Como proposto por Falcade, a implementação da Indicação Geográfica traz benefícios desde o econômico ao social, além das questões ambientais, discussão de extrema necessidade e que também nos faz refletir, novamente, sobre o território e seus atributos. Ao pensar as IGs, pensamos nas relações humanas em busca de um produto de qualidade, essa qualidade, muitas vezes particular, modificando a organização da sociedade, as relações econômicas de onde está inserida e, como citado anteriormente, a questão ambiental das áreas em que são desenvolvidos os produtos centrais.

Outro ponto a ser apresentado é o protagonismo do vinho, produto central que foi fundamental nos processos de certificação das IGs em diversas partes do globo, inclusive no Brasil. Percebemos que, após a indicação ocorrida em Porto, ao longo dos anos houve um aumento das certificações, majoritariamente ligadas às áreas vitivinícolas.

O número de regiões delimitadas ou de indicações geográficas existentes em países tradicionalmente vitivinícolas, nos dá uma idéia de sua importância: 351 na França, 245 na Itália, 235 na Alemanha, 36 na África do Sul, 33 na Espanha (BolletinodelCideao, 1992). Entre os países integrantes do MERCOLSUL, a Argentina era o único que possuía, do ponto de vista de regionalização duas denominações de origem em implementação: San Rafael e Lujan de Cuyo. Além da Argentina, nas Américas, o Chile implementou legislação de regionalização da produção de vinhos em 1979 e 1980 (HERNÁNDEZ, PSZCZÓLKOWSKI E BORDEU, 1992), embora já, em 1931, tivesse sido demarcada a região do Pisco. Nos EUA, a regionalização ocorreu em 1983, através das American ViticulturalAreas (AVA's) (FALCADE, 2005, p. 38/39).

Como apresentado por Falcade, percebemos uma presença de certificações em diversas regiões do planeta, cujo protagonismo é do vinho e dos arranjos territoriais dos produtores para que isso se desenvolva. É necessário endossar como o vinho e as Indicações Geográficas que possuem esse produto central são fundamentais no embasamento teórico sobre as certificações, sendo essenciais para o entendimento das diversas IGs do Brasil e do mundo.

Conforme consta no trecho do autor, é possível observar a centralidade das Indicações Geográficas que estão no continente europeu, em especial, França, Itália e Alemanha. Na América do Sul, devemos ressaltar, a Argentina e o Chile, ambos com territórios certificados pela questão vitivinícola.

O Brasil do início do século, não tinha debates e estruturação sobre as IGs, mas hoje vive uma realidade diferente. Quando falamos sobre a primeira Indicação Geográfica brasileira, estamos falando da Indicação Geográfica do Vale dos Vinhedos. Essa, como em diversas regiões mundiais, tem como produto central o vinho que, segundo o INPI, teve seu registro no dia 19/11/2002 como Indicação de 
Procedência, isto é, quando um produto torna o território reconhecido pelo desenvolvimento dele.

Para que possamos compreender como se instaurou a IG do Vale dos Vinhedos, temos que recorrer à década de 1990, na qual o Governo brasileiro realiza o aparato jurídico para as Indicações Geográficas no Brasil.

A Lei de propriedade Industrial (LPI) - Lei No 0.279, de 14. 05. 1996 concretizou a possibilidade de implementação e reconhecimento das Indicações Geográficas no Brasil (BRASIL, 1996) e a Resolução 075/2000, do Instituto Nacional de propriedade Industrial, as condições para o registro das Indicações Geográficas (INPI, 2000 apud. FALCADE, 2005, p. 145).

Como apresentado, a Lei da Propriedade Industrial (1996) sancionada pelo presidente da época, Fernando Henrique Cardoso, foi o marco governamental que permitiu implementar e reconhecer o processo de IGs do território brasileiro, o aparato legal. Deve-se lembrar o papel de determinados segmentos da sociedade como os produtores do Vale dos Vinhedos, que realizavam arranjo em seu território e se organizaram para que esse marco acontecesse.

Segundo Flores e Falcade (2019), é a partir da Lei da Propriedade Industrial de 1996, juntamente com a disseminação do tema, que ocorre o registro da primeira IG. A partir dessa lei, também ocorre o aumento gradativo de uma série de estudos sobre as certificações no território brasileiro.

Após a instauração da Lei, o setor vitivinícola da Região do Vale dos Vinhedos, através da Associação dos Produtores de Vinhos Finos dos Vales dos Vinhedos (APROVALE), inicia em pedido enviado ao INPI a instauração da Indicação Geográfica que foi descrita anteriormente.

Com as Indicação Geográfica do Vale dos Vinhedos, outras certificações começaram a surgir no território brasileiro, inclusive com outros produtos centrais, como a IG da Região do Cerrado Mineiro (2005), que possui o café como produto central, além da IG da Pampa Gaúcha da Campanha Meridional (2006), a qual tem a carne bovina como produto central. Ademais, é sempre importante ressaltar os produtores, juntamente com suas respectivas associações, cooperativas, conselheiros, dentre outros, que dispuseram de arranjo territórios para que as certificações ocorressem.

\section{Tipologia das Indicações Geográficas no Brasil}

Nesse tópico serão apresentadas as Indicações Geográficas presentes no território brasileiro e, posteriormente, as do estado de Minas Gerais, todas devidamente registradas e caracterizadas pelo INPI. É possivel perceber como as diversas IGs estão espacializadas por todo Brasil e são dotadas dos mais diversos produtos. Como discutido anteriormente, percebe-se a utilização e organização de um arranjo territorial para diversas atividades intercaladas nas mais diversas esferas econômicas, sociais e cultuais, desde produtos artesanais de comércio regional a produtos de cunho global dotados de várias tecnologias.

De acordo com o INPI (2019), há o registro de 79 Indicações Geográficas, sendo 57 Indicações de Procedência e 22 Denominação de Origem. Já inseridas na 
Denominação de Origem, temos 13 nacionais e 9 internacionais. De acordo com Caldas (2019), essas IGs expostas cresceram de forma significativa nas últimas duas décadas.

No Quadro 1 estão expostas as Indicações Geográficas do Brasil, com seus números vinculados ao INPI, seus Produtos Centrais (produtos protagonistas para que fossem territórios certificados), sua Data de Registro (fundamental para um entendimento temporal das certificações brasileiras) e seu tipo de IG, visto que no Brasil as certificações podem ocorrer de duas maneiras (Indicação de Procedência e Denominação de Origem).

Ao todo, foram colocadas 68 Indicações Geográficas no quadro, das 77 registradas, pois foram contabilizadas apenas as Nacionais. As IGs do Vale dos Vinhedos e Região do Cerrado Mineiro foram contabilizadas duas vezes, com seus dois registros no INPI, isso ocorreu pois ambas possuem tanto a Indicação de Procedência como também a Denominação de Origem.

A ordenação do Quadro 1 se deu pela data em que as Indicações Geográficas foram registradas no Instituto Nacional de Propriedade Industrial

Quadro 1. Brasil: Indicações Geográficas, Números de Registro, Produtos Centrais, Data de Registro e Tipo de IG (2020)

\begin{tabular}{|c|c|c|c|c|}
\hline Igs & Número no INPI & Produto Central & $\begin{array}{l}\text { Data de } \\
\text { Registro } \\
\end{array}$ & $\begin{array}{c}\text { Tipo } \\
\text { IG }\end{array}$ \\
\hline Vale dos Vinhedos & IG200002 & Vinho & 19/11/2002 & IP \\
\hline Região do Cerrado Mineiro & IG990001 & Café & $14 / 04 / 2005$ & IP \\
\hline $\begin{array}{c}\text { Pampa Gaúcho da Campanha } \\
\text { Meridional }\end{array}$ & IG200501 & Carne Bovina & $12 / 12 / 2006$ & IP \\
\hline Paraty & IG200602 & Cachaça & $10 / 07 / 2007$ & IP \\
\hline Vale do Sinos & IG200702 & Couro & 19/05/2009 & IP \\
\hline $\begin{array}{c}\text { Vale do Submédio São } \\
\text { Francisco }\end{array}$ & IG200701 & Uva e Manga & 07/07/2009 & IP \\
\hline Pinto Bandeira & IG200803 & Vinho & $13 / 07 / 2010$ & IP \\
\hline Litoral Norte Gaúcho & IG200801 & Arroz & $24 / 08 / 2010$ & DO \\
\hline Costa Negra & IG200907 & Camarões Marinhos & $16 / 08 / 2011$ & $\mathrm{DO}$ \\
\hline $\begin{array}{c}\text { Região do Jalapão do estado do } \\
\text { Tocantins }\end{array}$ & IG200902 & $\begin{array}{l}\text { Artesanato em } \\
\text { Capim Dourado }\end{array}$ & $30 / 08 / 2011$ & IP \\
\hline Pelotas & IG200901 & Doces & $30 / 08 / 2011$ & IP \\
\hline Goiabeiras & IG201003 & Panelas de Barro & 04/10/2011 & IP \\
\hline Serro & IG201001 & Queijo & $13 / 12 / 2011$ & IP \\
\hline São João del-Rei & IG201010 & $\begin{array}{l}\text { Artesanato em } \\
\text { Estanho }\end{array}$ & 07/02/2012 & IP \\
\hline Franca & IG201012 & Calçados & 07/02/2012 & IP \\
\hline Vales da Uva Goethe & IG201009 & Vinho & $14 / 02 / 2012$ & IP \\
\hline Canastra & IG201002 & Queijo & $13 / 03 / 2012$ & IP \\
\hline Pedro II & IG201014 & $\begin{array}{l}\text { Opala e Joias } \\
\text { Artesanais }\end{array}$ & 03/04/2012 & IP \\
\hline $\begin{array}{c}\text { Região Pedra Carijó Rio de } \\
\text { Janeiro }\end{array}$ & IG201004 & Rocha Gnaisse & 22/05/2012 & DO \\
\hline $\begin{array}{l}\text { Região Pedra Madeira Rio de } \\
\text { Janeiro }\end{array}$ & IG201005 & Rocha Gnaisse & $22 / 05 / 2012$ & DO \\
\hline $\begin{array}{c}\text { Região Pedra Cinza Rio de } \\
\text { Janeiro }\end{array}$ & IG201006 & Rocha Gnaisse & 22/05/2012 & DO \\
\hline Cachoeiro de Itapemirim & IG201007 & Mármore & 29/05/2012 & IP \\
\hline Manguezais de Alagoas & IG201101 & Própolis & $17 / 07 / 2012$ & DO \\
\hline
\end{tabular}




\begin{tabular}{|c|c|c|c|c|}
\hline Norte Pioneiro do Paraná & IG200903 & Café & $25 / 09 / 2012$ & $\mathrm{IP}$ \\
\hline Linhares & IG200909 & Cacau & $31 / 07 / 2012$ & IP \\
\hline Vale dos Vinhedos & IG201008 & Vinho & 25/09/2012 & DO \\
\hline Paraíba & IG200904 & Algodão & $16 / 10 / 2012$ & IP \\
\hline Região de Salinas & IG200908 & Cachaça & $16 / 10 / 2012$ & $\mathrm{IP}$ \\
\hline Porto Digital & IG201103 & $\begin{array}{l}\text { Tecnologia de } \\
\text { Informação }\end{array}$ & $11 / 12 / 2012$ & IP \\
\hline Altos Montes & BR402012000002-0 & Vinho & $11 / 12 / 2012$ & IP \\
\hline Divina Pastora & IG201107 & Renda em Lacé & $26 / 12 / 2012$ & $\mathrm{IP}$ \\
\hline São Tiago & 201104 & Biscoito & 05/02/2013 & IP \\
\hline Alta Mogiana & IG200703 & Café & $17 / 09 / 2013$ & IP \\
\hline Mossoró & IG201108 & Melão & $17 / 09 / 2013$ & IP \\
\hline Cariri Paraibano & BR402012000005-5 & Renda Renascença & $24 / 09 / 2013$ & IP \\
\hline Monte Belo & BR402012000006-3 & Vinho & $01 / 10 / 2013$ & IP \\
\hline Região do Cerrado Mineiro & IG201011 & Café & $31 / 12 / 2013$ & DO \\
\hline Piauí & BR402012000004-7 & Cajuína & $26 / 08 / 2014$ & IP \\
\hline Rio Negro & BR2012000003-9 & Peixe & 09/09/2014 & IP \\
\hline Microrregião Abaíra & BR402012000001-2 & Cachaça & $14 / 10 / 2014$ & IP \\
\hline Pantanal & BR2013000004-0 & Mel & $10 / 03 / 2015$ & $\mathrm{IP}$ \\
\hline Farroupilha & BR402014000006-9 & Vinho & $14 / 07 / 2015$ & IP \\
\hline Ortigueira & BR412013000002-0 & Mel & 01/09/2015 & DO \\
\hline Maracaju & BR402014000007-7 & Linguiça & $24 / 11 / 2015$ & IP \\
\hline Região de Mara Rosa & BR402013000006-6 & Açafrão & 02/02/2016 & $\mathrm{IP}$ \\
\hline $\begin{array}{l}\text { Região das Lagoas Mundaú- } \\
\text { Manguaba }\end{array}$ & BR402014000012-3 & Bordado Filé & 19/04/2016 & $\mathrm{IP}$ \\
\hline Carlópolis & BR402015000008-8 & Goiaba & $17 / 05 / 2016$ & $\mathrm{IP}$ \\
\hline Região de Pinhal & BR402014000001-8 & Café & $19 / 07 / 2016$ & $\mathrm{IP}$ \\
\hline $\begin{array}{c}\text { Região da Própolis Verde de } \\
\text { Minas Gerais }\end{array}$ & BR412013000005-4 & Própolis & 06/09/2016 & DO \\
\hline Região São Bento de Urânia & BR402014000004-2 & Inhame & $20 / 09 / 2016$ & $\mathrm{IP}$ \\
\hline Marialva & BR402015000003-7 & Uva & $27 / 06 / 2017$ & $\mathrm{IP}$ \\
\hline São Matheus & BR402015000011-8 & Erva-mate & $27 / 06 / 2017$ & $\mathrm{IP}$ \\
\hline Oeste do Paraná & BR402015000012-6 & Mel & $04 / 07 / 2017$ & $\mathrm{IP}$ \\
\hline Cruzeiro do Sul & BR402015000002-9 & $\begin{array}{l}\text { Farinha de } \\
\text { Mandioca }\end{array}$ & $22 / 08 / 2017$ & $\mathrm{IP}$ \\
\hline Maués & BR402015000001-0 & Guaraná & $16 / 01 / 2018$ & IP \\
\hline Sul da Bahia & BR402014000011-5 & $\begin{array}{l}\text { Amêndoas de } \\
\text { cacau }\end{array}$ & $24 / 04 / 2018$ & IP \\
\hline Colônia Witmarsum & BR402015000010-0 & Queijo & $24 / 04 / 2018$ & $\mathrm{IP}$ \\
\hline Venda Nova do Imigrante & BR402014000002-6 & Socol & $12 / 06 / 2018$ & IP \\
\hline Banana da Região de Corupá & BR412016000003-6 & Banana & $28 / 08 / 2018$ & DO \\
\hline Sabará & BR402014000009-3 & $\begin{array}{l}\text { Jabuticaba e } \\
\text { derivados }\end{array}$ & 23/10/2018 & $\mathrm{IP}$ \\
\hline Tomé-Açu & BR402014000010-7 & Cacau & 29/01/2019 & $\mathrm{IP}$ \\
\hline Oeste da Bahia & BR402014000005-0 & Café & $14 / 05 / 2019$ & $\mathrm{IP}$ \\
\hline Pirenópolis & BR402017000008-3 & Joias em Prata & 09/07/2019 & $\mathrm{IP}$ \\
\hline Uarini & BR402017000003-2 & $\begin{array}{l}\text { Farinha de } \\
\text { Mandioca }\end{array}$ & $27 / 08 / 2019$ & $\mathrm{IP}$ \\
\hline Capanema & BR402015000009-6 & Melado & $17 / 12 / 2019$ & $\mathrm{IP}$ \\
\hline Campos de Cima da Serra & BR412017000006-3 & Queijo & 03/03/2020 & DO \\
\hline Campanha Gaúcha & BR402017000009-1 & Vinho & 05/05/2020 & IP \\
\hline Mantiqueira de Minas & IG200704 & Café & 09/06/2020 & $\mathrm{DO}$ \\
\hline Novo Remanso & BR402017000004-0 & Abacaxi & 09/06/2020 & $\mathrm{IP}$ \\
\hline Caicó & BR402018000001-9 & Bordado & $23 / 06 / 2020$ & IP \\
\hline
\end{tabular}

Fonte: Instituto Nacional de Propriedade Industrial (2019)

Organização e elaboração: (o autor). (2020) 
Cada uma das Indicações Geográficas expostas anteriormente possuem informações e características com toda uma trajetória, tendo suas respectivas cooperativas, associações, dentre outras, ou seja, conseguindo formas de organização territorial para atribuir valor aos seus produtos. Ainda nessa discussão, nota-se que, quanto mais recente o pedido e a concessão de certificação, cada vez são exigidas informações mais complexas, como descrições mais profundas, delimitações de áreas por coordenadas geográficas, ou seja, um processo que, além de crescente, se torna também mais emaranhado.

Para Caldas (2019), as certificações iniciam no Brasil nos anos 2000:

O primeiro registro de indicação geográfica no INPI foi o da Indicação de Procedência do Vale dos Vinhedos (2000), a qual teve o apoio institucional da Embrapa Uva e Vinho da Universidade de Caxias do Sul. Em 2005, houve o registro da Indicação de Procedência Cerrado Mineiro (CALDAS, 2019 , p. 10).

Observa-se, por conseguinte, como essas duas regiões presentes, respectivamente, nos estados do Rio Grande do Sul e em Minas Gerais, e como produtos centrais, também respectivamente, o vinho e o café, foram protagonistas e iniciaram as certificações no território brasileiro. Atualmente, são as únicas que possuem tanto a Indicação de Procedência como a Certificação de Origem.

Uma dinâmica que pode ser observada no quadro anterior é como as IGs estão presentes tanto no meio rural, onde há o seu predomínio, como também no meio urbano:

\begin{abstract}
Estão presentes, em sua grande maioria, no campo, como, por exemplo, as indicações geográficas de Café do Cerrado (MG), Capim Dourado (Jalapão -TO), cachaça de Salinas (MG), carne do Pampa Gaúcho (RS), entre outras; mas, também, estão presentes nas cidades, como, por exemplo, as indicações geográficas Porto Digital (Cidade de Recife-PE), Doces de Pelotas (Cidade de Pelotas-RS), Panelas de Barro de Goiabeiras (Cidade de Vitória - ES) (CALDAS, 2019, p. 12).
\end{abstract}

Esse predomínio posto pelo campo, se dá em sua maioria, pelos produtos centrais vinculados às Igs. Muitos são produtos agroalimentares vinculados ao campo que vai desde produções "artesanais", como a produção de Queijo Serro, até um espaço globalizado, como o Café do Cerrado Mineiro. Essas produções permeiam também o meio urbano, com polos tecnológicos, calçados, dentre outros. Desse modo, pode estabelecer uma relação campo-cidade pois esses meios interagem, ambos planejam e dispõem de associações, cooperativas, agem sobre as dinâmicas do seu território, se transpõem e se complexam.

Esse debate retoma a uma argumentação de como as características bases da Geografia são expostas a todo momento ao se estudar as Indicações Geográficas, da Cartografia, Regionalização do Espaço, Descrição da Paisagem, Geografia Rural e Urbana e Geografia Política; ao perceber as dinâmicas desde a Geografia Física, com aspectos naturais, até a Geografia Humana, com seus aspectos culturais e relações de poder. Infere-se, portanto, uma fonte de estudos imensuráveis e que rodeia as mais diversas categorias de análise, mostrando como essa discussão é profunda. 
Análogo a isso, outra característica marcante é como as Indicações Geográficas estão distribuídas por todo território brasileiro, desde o estado do Rio Grande do Sul ao estado do Amazonas, isso elenca diversidades regionais e características diferentes, visto isso, a distribuição das IGs ocorre pelas 5 regiões brasileiras, segundo o IBGE, como demonstra o Gráfico 1.

Gráfico 1 - Brasil: Indicações Geográficas (IGs) por Regiões (2020)

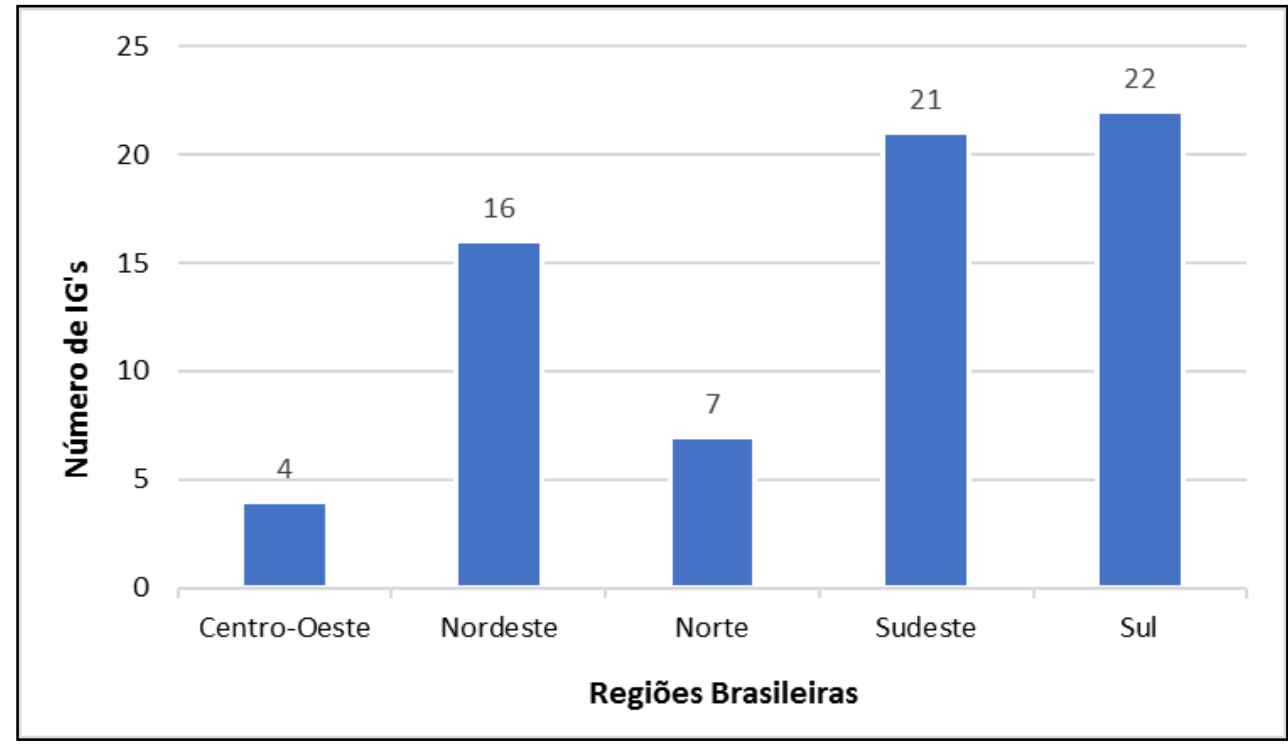

Fonte: Instituto Nacional de Propriedade Industrial (2019)

Organização: (AUTOR) (2020)

Ao observar o Gráfico 1, é possível analisar, primeiramente, como as Indicações Geográficas se encontram distribuídas no território brasileiro, estão espalhadas pelas cinco regiões, fato que mostra como esse processo, que se enraizou nos anos $2000 \mathrm{com}$ a IG do Vale dos Vinhedos, se expandiu e se espacializou pelo Brasil.

Verifica-se, no entanto, o predomínio das Regiões Sul com 22 IGs e Sudeste com 21 IGs, lembrando que as IGs do Vale dos Vinhedos e Região do Cerrado Mineiro foram contabilizadas, como no Quadro 1, duas vezes, pois possuem tanto a Indicação de Procedência como Denominação de Origem. Esse predomínio nessas duas regiões se dá por diversos fatores, dentre eles, uma herança histórica colonial, como no caso da Região Sul, visto que as certificações possuem uma estratégia extremamente presente nos países europeus. Outro fator, são as formas de organização territorial dessa região, identificando grandes cooperativas e associações que se colocam em diversas discussões econômicas e culturais, fato fundamental para que ocorra as certificações.

Em contrapartida, a região que apresenta o menor número de Indicações Geográficas é a região Centro-Oeste, com apenas quatro IGs, isso não quer dizer que a região tenha menos ligações com as questões culturais e valorização dos seus produtos, mas pode-se levantar um pensamento de que a lógica produtiva nessa região é muito ligada às commodities, em outros termos, um produto de baixo valor agregado, que não diferencia por quem os produziu ao ser armazenado e 
possui preço ditado pela oferta e procura internacional, sendo essa estrutura um desacordo com a lógica das Indicações Geográficas. Também temos a região Nordeste e Norte, com, respectivamente, quinze e seis IGs, com o intuito de mostrar como todas regiões do territorial nacional, em algumas mais e outras menos, possuem as certificações.

Outras características dessas Indicações Geográficas são como elas possuem os mais diversos produtos centrais, no Gráfico 2 é possível perceber como eles são variados:

Gráfico 2 - Brasil: Produtos vinculados às IGs registradas no país em porcentagem (2020)

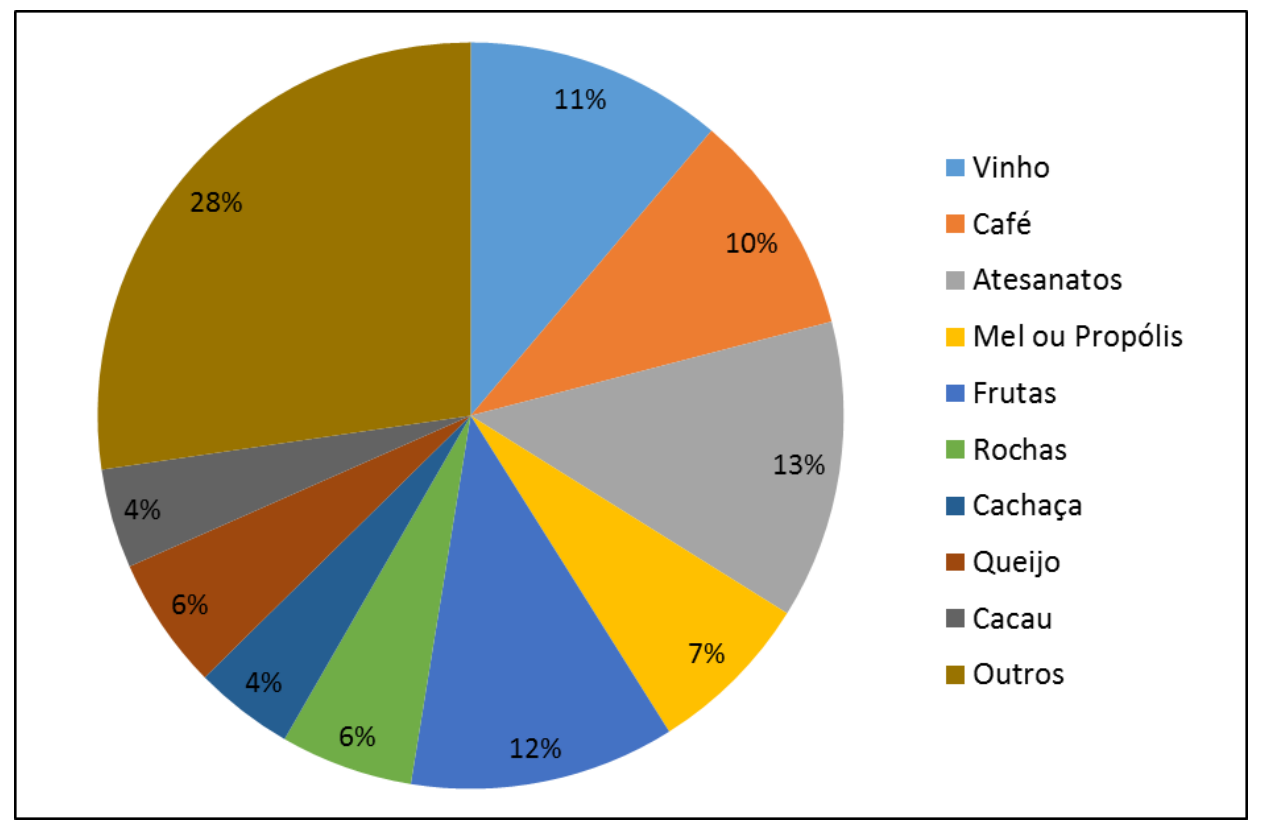

Fonte: Instituto Nacional de Propriedade Industrial (2019)

Organização: (AUTOR) (2020)

O Gráfico 2 traz informações sobre os principais produtos vinculados a cada Indicação Geográfica, visto que esses dispõem da centralidade para que a IG ocorra, pois a partir desses produtos, sucedem arranjos territoriais e organizações espaciais, os quais levarão à certificação. O Gráfico 2 emprega da metodologia proposta por Flores e Falcade (2019), as quais organizam esses produtos desta forma em seus estudos.

Nota-se a presença de produtos com grande diversidade, desde produtos de gênero primário (café e cacau), artesanatos (peças em estanho), até produtos tecnológicos (tecnologia de informação), ou seja, IGs que possui diversos produtos, os quais, individualmente, possuem suas caracterizações, algo que torna o estudo das Indicações algo complexo. Podemos também elencar, no Gráfico 2, 0 predomínio de Indicações Geográficas voltadas para artesanatos, frutas, mel ou própolis, vinho e café, percebendo, assim, dentre os destacados, o predomínio de produtos agroalimentares. 
Em síntese, ao apresentarmos as Indicações Geográficas presentes no Brasil, é possível pontuar como as Indicações Geográficas são diversas e dotadas de diferentes dinâmicas e estão distribuídas por todas as regiões nacionais (com predomínio do Sul e Sudeste) e apresenta vários produtos com suas distintas características, como áreas, associações, entre outros. Esse fato leva à reflexão de como múltiplas forças, das mais variadas escalas, utilizam desses territórios como forma de exercer poder sobre ele, além de modificá-lo de acordo com suas necessidades e demandas, visto isso, deve-se sempre ocorrer uma profunda percepção da Categoria Geográfica Território.

\section{Indicações Geograficas em Minas Gerais}

O estado de Minas Gerais é dotado de grandes diversidades, sendo o quarto estado em extensão territorial, segundo maior em população e o maior estado brasileiro em número de municípios, ou seja, um estado marcado por grandes proporções que vão desde o território até população, possibilitando, assim, várias culturas, povos e costumes.

Ao tratarmos de Indicações Geográficas, essa realidade não é diferente, Minas Gerais possui essas certificações por todo seu território, cada uma delas com suas características e dinâmicas. Segundo o INPI (2019), o estado possui dez Indicações Geográficas, sendo oito delas Indicação de Procedência e duas delas Denominação de Origem, vale endossar que o estado se insere na Região Sudeste do Brasil, a qual fica atrás apenas da Região Sul, que dispõe do maior número de IGs nacionais.

No Quadro 2, segue as IGs presentes no território estadual, sendo contabilizadas dez certificações, a Região do Cerrado Mineiro, como no Quadro 1, é exposta duas vezes com seus dois registros no INPI, isso por ser a única no estado a conseguir a Indicação de Procedência e a Denominação de Origem.

Quadro 2 - Minas Gerais: Indicações Geográficas, Números de Registro, Produtos Centrais, Data de Registro e Tipo de IG (2020)

\begin{tabular}{|c|c|c|c|c|}
\hline IGs & Número no INPI & Produto Central & $\begin{array}{l}\text { Data de } \\
\text { Registro }\end{array}$ & $\begin{array}{c}\text { Tipo de } \\
\text { IG }\end{array}$ \\
\hline Região do Cerrado Mineiro & IG990001 & Café & $14 / 04 / 2005$ & IP \\
\hline Serro & IG201001 & Queijo & $13 / 12 / 2011$ & IP \\
\hline São João del-Rei & IG201010 & $\begin{array}{l}\text { Artesanato em } \\
\text { Estanho }\end{array}$ & 07/02/2012 & IP \\
\hline Canastra & IG201002 & Queijo & 13/03/2012 & IP \\
\hline Região de Salinas & IG200908 & Cachaça & $16 / 10 / 2012$ & IP \\
\hline São Tiago & 201104 & Biscoito & 05/02/2013 & IP \\
\hline Região do Cerrado Mineiro & IG201011 & Café & $31 / 12 / 2013$ & DO \\
\hline $\begin{array}{c}\text { Região da Própolis Verde de } \\
\text { Minas Gerais }\end{array}$ & $\begin{array}{l}\text { BR412013000005- } \\
4\end{array}$ & Própolis & 06/09/2016 & DO \\
\hline Sabará & $\begin{array}{c}\text { BR402014000009- } \\
3\end{array}$ & $\begin{array}{c}\text { Jabuticaba e } \\
\text { derivados }\end{array}$ & $23 / 10 / 2018$ & IP \\
\hline Mantiqueira de Minas & IG200704 & Café & 09/06/2020 & DO \\
\hline
\end{tabular}

Fonte: Instituto Nacional de Propriedade Industrial (2019)

Organização: (AUTOR) (2020) 
Ao observar o quadro, podemos constatar como as IGs estão presentes no estado, cada uma com suas características. Algumas de registro mais recentes, outras bem antigas, algumas ligadas à produção mais artesanal, outras ligadas a padrões produtivos globalizados, com isso, essa constatação reforça a ideia de complexidade do estado.

Outra observação é como as IGs estão espalhadas pelas mais diversas Mesorregiões do estado (se contabilizam segundo o IBGE como doze mesorregiões), como por exemplo: a IG de Sabará, localizada na Mesorregião Metropolitana de Belo Horizonte; IG da região de Salinas, localizada na Mesorregião do Norte de Minas; IG de São João del-Rei, localizada na Mesorregião de Campo das Vertentes, em síntese, podemos observar como estão distribuídas por todo território mineiro, como apresenta o Mapa 1.

Mapa 1 - Minas Gerais: Localização das Indicações Geográficas (IGs) do estado

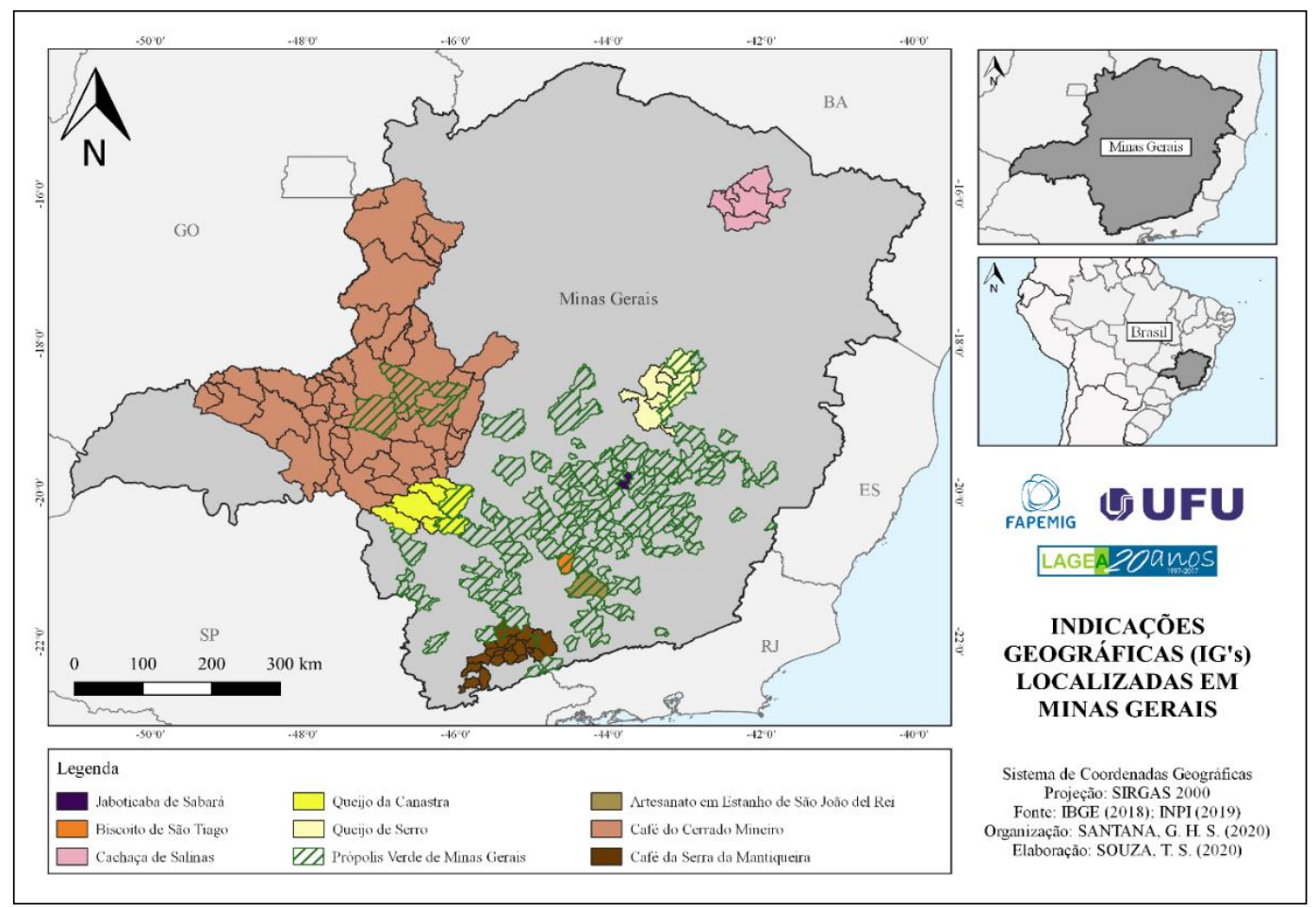

Fonte: IBGE (2019); INPI (2019)

Organização: (AUTOR) (2020)

Também podemos elencar como a característica espacial dessas Indicações Geográficas são diversas. Além dessas áreas estarem distribuídas pelo estado, como exposto anteriormente, elas também ocupam diversas áreas de tamanhos diferentes. Como exemplo, podemos apresentar a IG de São Tiago $\left(572,33 \mathrm{~km}^{2}\right)$ que, segundo o DataSebrae (2018), possui sua área delimitada, coincidentemente, igual ao do município de São Tiago, ela abrange uma área municipal. Já ao falarmos da IG da Região de Salinas (2541,99 km²), também segundo o DataSebrae (2018), abrange a totalidade dos municípios de Salinas e Novorizonte e parte dos municípios de Taiobeiras, Rubelita, Santa Cruz de Salinas e Fruta de Leite, todos esses situados ao norte do estado, ou seja, diferentemente da IG de São Tiago que 
apresentava sua área em apenas um município, a IG de Salinas apresenta um pequeno conjunto de municípios, em outros termos, características espaciais diferentes.

Seguindo esse raciocínio, podemos trazer a Região do Cerrado Mineiro que, também segundo o DataSebrae (2018), se dá em 55 municípios, abrangendo as regiões de Triângulo Mineiro, Alto Paranaíba e parte do Alto São Francisco e do Noroeste, isso corresponde a uma área superior a 234 mil hectares de café plantado. Em relação aos exemplos anteriores, uma área bem superior, IGs que vão desde um município até uma gama de 55 municípios como exemplificado. A diferenciação da área apresentada está muito ligada a qual produto é desenvolvido na IG, visto que diferentes produtos passam por diferentes processos produtivos e, assim, necessitam de extensões de áreas distintas.

Cada IG é dotada de complexidades e peculiaridades, nos fazendo perceber como o arranjo territorial pelas quais as certificações se dão ocorrem de maneiras diferentes, em síntese, cada indivíduo, instituição, cooperativas exercem poder e modificam seu território de acordo com seus anseios futuros. Essas diferenças também podem ser observadas no Gráfico 3, que apresenta os produtos centrais de cada IG presente no estado de Minas Gerais.

\section{Gráfico 3 - Minas Gerais: Produtos vinculados as IGs registradas no estado em porcentagem (2020)}

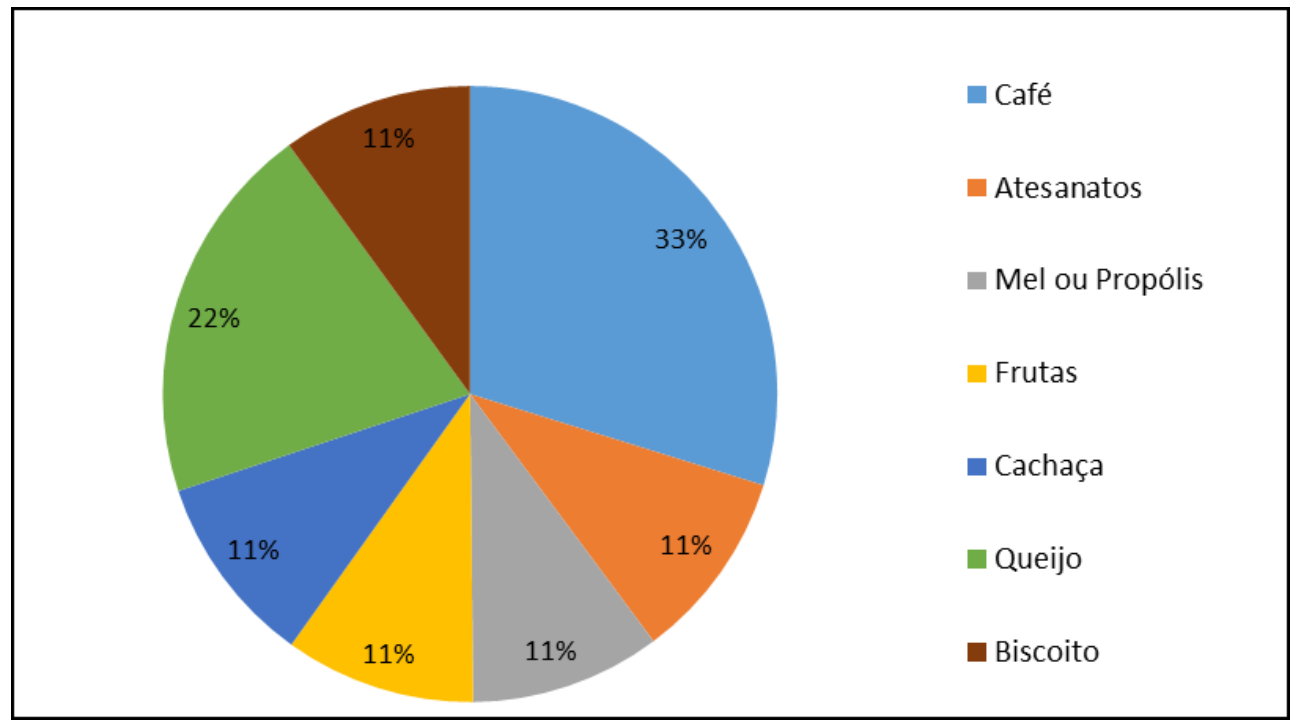

Fonte: Instituto Nacional de Propriedade Industrial (2019)

Organização: (AUTOR) (2020)

No Gráfico 3, que segue a mesma metodologia dos expostos anteriormente, podemos observar uma grande variedade de produtos centrais vinculados às Indicações Geográficas do estado de Minas Gerais, são produtos que vão desde agroalimentares, em que são predominantes, até artesanatos, como por exemplo, o artesanato em estanho. Essa grande diversidade ocorre tanto no estado como também é característica das IGs no território nacional, territórios diversos que realizam seu arranjo de acordo com suas especialidades. 
Ainda sobre o gráfico, nota-se no estado, o predomínio de dois produtos: o Café, Região da Serra da Mantiqueira de Minas Gerais (IP) e Região do Cerrado Mineiro (IP e DO), e o Queijo, Canastra (IP) e Serro (IP). São produtos de grande importância tanto na questão econômica e produtiva, como também marcas do cidadão, do indivíduo de Minas Gerais, do "mineiro em si", ou seja, questões econômicas e culturais presentes nesses produtos e, consequentemente, nas suas respectivas Indicações Geográficas.

\section{Considerações Finais}

Como uma discussão final, é necessário destacar a íntima relação entre as Indicações Geográficas e a categoria Território, pois ambas estabelecem uma relação mútua, na qual as IGs e os diversos arranjos levados por elas são fundamentais para modificaçãoterritório, bem como o território e suas características, únicas e fundamentais para as certificações, garantindo a particularidade exigida por ela.

Outro ponto dessa relação é como ambas estão intimamente ligadas ao exercício de poder de determinados agentes, sendo protagonistas o poder econômico, o poder político e o poder cultural, capazes de modificar tanto o território como as indicações presentes neles.

Deve-se evidenciar também a grande diversidade das Indicações Geográficas brasileiras, além do seu aumento quantitativo e qualitativo que, no primeiro semestre de 2020, contavam com 79 Indicações Geográficas, sendo elas 57 Indicações de Procedência e 22 Denominação de Origem.

De maneira aprofundada, deve-se destacar tambem o estado de Minas Gerais, apresentando dez Indicações Geográficas espalhadas por seu território contendo diversas características, como diferentes produtos centrais, áreas de abrangência, capital investido, dentre outros. É um estado de grande potencial nas suas certificações, desde o tradicional Queijo Canastra, com raizes históricas, ao moderno Café do Cerrado, com produtos ligados ao mercado global e ao meio técnico-científico-informacional.

Em síntese, nota-se a Indicação Geográfica diretamente ligada ao território e aos arranjos estabelecidos no mesmo, como também é possível perceber o poder político, econômico e cultural, podendo um sobressair sobre outro em determinada IG, moldando as certificações e seus respectivos produtos centrais.

Agradecimento

À Fundação de Amparo a Pesquisa do Estado de Minas Gerais (FAPEMIG) pela bolsa de Mestrado concedida no decorrer do ano de 2020.

\section{Referências}

BRASIL. Lei nำ 9.279, de 14 de maio de 1996. Regula direitos e obrigações relativos à propriedade industrial. Disponível em: http://www.planalto.gov.br/ccivil_03/Leis/L9279.htm. Acesso em: jul. 2020.

CALDAS, A. dos S. Indicações Geográficas: valorização e saber fazer nos territórios 
da propriedade intelectual. In: ENCONTRO NACIONAL DE PÓS-GRADUAÇÃO E PESQUISA EM GEOGRAFIA, XIII., 2019, São Paulo. Anais... [...] São Paulo, 2019.

DATASEBRAE. Indicações Geográficas Brasileiras. 2018. Disponível em: https://datasebrae.com.br/indicacoesgeograficas/. Acesso em: jul. 2020.

DATASEBRAE. Região de São João del Rei. 2018. Disponível em: https://datasebrae.com.br/ig-sao-joao-del-rei/. Acesso em: jul. 2020.

FLORES, S. S.; FALCADE, I. A Pesquisa sobre Indicações Geográficas no Brasil: Um estudo bibliométrico. Revista Ingi, Aracaju, v. 3, n. 2, p. 290-305, 2019.

FALCADE, I. Indicações Geográficas: o caso da região com indicação de procedência Vale dos Vinhedos. 2005. 109 f. Dissertação (Mestrado em Geografia) Universidade Federal do Rio Grande do Sul, Porto Alegre, 2005.

INSTITUTO BRASILEIRO DE GEOGRAFIA E ESTATÍSTICA (IBGE). Portal de Mapas: Bases cartográficas. Disponível em: https://portaldemapas.ibge.gov.br/portal.php\#mapa202374. Acesso em: jul. 2020.

INSTITUTO NACIONAL DA PROPRIEDADE INDUSTRIAL (INPI). Indicação Geográfica no Brasil. Disponível em: http://antigo.inpi.gov.br/menuservicos/indicacao-geografica/indicacao-geografica-no-brasil. Acesso em: jul. 2020.

NIERDELE, P. A.; VITROLLES, D. Indicações Geográficas e qualificação no setor vitivinícola brasileiro. Estudos Sociedade e Agricultura, Rio de Janeiro, v. 18, no․ 1, p. 5-55, 2010.

SOUZA, M. J. L. de. "Território" da divergência (e da confusão): em torno das imprecisas fronteiras de um conceito fundamental. In: SAQUET, M. A.; SPOSITO, E. S. (Orgs.) Territórios e territorialidades: teorias, processos e conflitos. São Paulo: Expressão Popular, Unesp, 2009, p. 57-72.

SOUZA, M. J. L. O território: sobre espaço e poder, autonomia e desenvolvimento. In: CASTRO, I. E.; GOMES. P. C. da C.; CORRÊA, R. L. (Orgs.). Geografia: conceitos e temas. $2^{a}$ ed. Rio de Janeiro: Bertrand Brasil, 2000. 